\title{
Comparing common reasons for inpatient and outpatient visits between commercially-insured duloxetine or pregabalin initiators with fibromyalgia
}

This article was published in the following Dove Press journal:

Journal of Pain Research

30 October 2012

Number of times this article has been viewed

\author{
Yang Zhao' \\ Peter Sun ${ }^{2}$ \\ Mark Bernauer ${ }^{3}$ \\ 'Eli Lilly and Company, ${ }^{2}$ Kailo \\ Research Group, ${ }^{3}$ Optumlnsight, \\ Indianapolis, IN, USA
}

Background: The purpose of this study was to examine the main reasons for inpatient or outpatient visits after initiating duloxetine or pregabalin.

Methods: Commercially insured patients with fibromyalgia and aged 18-64 years who initiated duloxetine or pregabalin in 2006 with 12-month continuous enrollment before and after initiation were identified. Duloxetine and pregabalin cohorts with similar demographics, preindex clinical and economic characteristics, and pre-index treatment patterns were constructed via propensity scoring stratification. Reasons for inpatient admissions, physician office visits, outpatient hospital visits, emergency room visits, and primary or specialty care visits over the 12 months post-index period were examined and compared. Logistic regression was used to assess the contribution of duloxetine versus pregabalin initiation to the most common reasons for visits, controlling for cross-cohort differences.

Results: Per the study design, the duloxetine $(n=3711)$ and pregabalin $(n=4111)$ cohorts had similar demographics (mean age 51 years, $83 \%$ female) and health care costs over the 12 -month pre-index period. Total health care costs during the 12-month post-index period were significantly lower for duloxetine patients than for pregabalin patients $(\$ 19,378$ versus $\$ 27,045$, $P<0.05)$. Eight of the 10 most common reasons for inpatient admissions and outpatient hospital (physician office, emergency room, primary or specialty care) visits were the same for both groups. Controlling for cross-cohort differences, duloxetine patients were less likely to be hospitalized due to an intervertebral disc disorder or major depressive disorder, to have a physician office visit due to nonspecific backache/other back/neck pain (NB/OB/NP) disorder, or to go to specialty care due to a soft tissue, NB/OP/NP, or intervertebral disc disorder. However, duloxetine patients were more likely to have a primary care visit due to a soft tissue disorder, essential hypertension, or other general symptoms.

Conclusion: Among similar commercially insured patients with fibromyalgia who initiated duloxetine or pregabalin, duloxetine patients had significantly lower health care costs over the 12 -month post-index period. The leading reasons for inpatient or outpatient visits were also somewhat different.

Keywords: duloxetine, pregabalin, inpatient admissions, physician office visits, outpatient hospital visits, emergency room, primary care visits, specialty care visits

\section{Introduction}

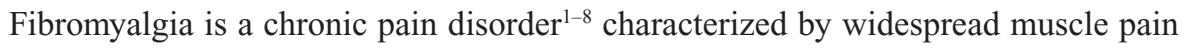
and a heightened and painful response to gentle touch at multiple tender points. ${ }^{1-10}$ About 4-10 million people in the US and 3\%-6\% of the world population have fibromyalgia, ${ }^{1,4-7,11-18}$ and the highest prevalence occurs among women and people with a family history of fibromyalgia. ${ }^{47,9}$ Patients with fibromyalgia often experience
Correspondence: Peter Sun

Kailo Research Group

8247 Jo Ellen Drive

Fishers, IN 46038, USA

Email psun00I@yahoo.com 
other conditions, such as fatigue, sleep deprivation, and depression, ${ }^{19-22}$ which may have a negative impact on general functioning and overall quality of life..$^{23-25}$

Up until now, treatment for fibromyalgia has been mainly aimed at symptom management through pharmacologic therapy, behavioral intervention, physical therapy, exercise, or alternative medicines. ${ }^{26-34}$ Among the various pharmacologic therapies used by patients with fibromyalgia, duloxetine (2008), pregabalin (2007), and milnacipran (2009) are the only ones approved for the management of fibromyalgia by the US Food and Drug Administration. A recent publication from our previous study among commercially insured patients with fibromyalgia suggested that individuals who initiated duloxetine had better medication compliance and significantly lower direct medical costs than similar patients (demographics, comorbidities, prior total health care costs, and prior medication treatment) who initiated pregabalin. ${ }^{35}$ Although our previous study found that most of the cost difference was from outpatient services followed by inpatient care, ${ }^{35}$ we did not examine what medical conditions led to inpatient admissions or outpatient visits among similar patients with fibromyalgia who initiated duloxetine or pregabalin, and we also did not explore how different health care services were provided for these patients.

Using the same study design on the same patients as examined in our previous study, ${ }^{35}$ we used a comprehensive disease classification to examine and compare the most common reasons leading to inpatient admissions, hospital outpatient visits, physician office visits, emergency room visits, primary care visits, and specialty care visits among similar commercially insured patients with fibromyalgia who initiated duloxetine versus pregabalin in 2006. Logistic regression was used to assess the contribution of initiation of duloxetine versus pregabalin to the most common reasons, controlling for cross-cohort differences.

\section{Materials and methods}

\section{Data source}

Deidentified insurance claims from the Thomson Reuters MarketScan ${ }^{\circledR}$ Commercial Claims databases 2005-2007 were examined. The MarketScan databases are compliant with the Health Insurance Portability and Accountability Act, and contain enrollment details, inpatient and outpatient data, and pharmacy claims for individuals covered by over 100 self-insured employers and health plans geographically located throughout the United States. All files can be linked via a unique personal identifier. Demographics, health plan enrollment, health care utilization and costs in inpatient and outpatient settings, and outpatient pharmacy claims are provided for each individual.

\section{Design and duration}

This study used a retrospective cohort design. Patients with fibromyalgia who initiated duloxetine or pregabalin in 2006 were grouped into duloxetine or pregabalin cohorts based on the medication initiated. Initiation was defined as a 90-day absence of the initiated medication, with the first initiation date as the index date. The study duration included a 12-month period preceding initiation (pre-index period) and a 12-month period following initiation (post-index period).

\section{Sample selection}

As described in our previous publication, ${ }^{35,36}$ individuals who initiated (a 90-day medication gap) duloxetine or pregabalin in 2006 were first identified. All selected patients were required to: have at least one fibromyalgia diagnosis (ICD-9-CM 729.1) during the 12-month pre-index period, be aged between 18 and 64 years as of the index date, have 12 -month continuous enrollment in the pre-index and postindex periods, and have $31+$ total duloxetine or pregabalin supply days over the entire 12-month post-index period. Duloxetine initiators with a diagnosis of diabetic peripheral neuropathic pain (ICD-9CM 250.6x, 357.2x) or depression (ICD-9-CM 296.2x, 296.3x, 300.4x, 309.1x, or 311.xx) during the 12-month pre-index period were excluded. Pregabalin patients with a diagnosis of diabetic peripheral neuropathic pain, post-herpetic neuralgia (ICD-9-CM 053.11, 053.12, 053.19), or epilepsy (ICD-9-CM 345.xx) over the 12-month pre-index period were also excluded.

As in the previous study, ${ }^{35,36}$ propensity score stratification was applied to construct duloxetine and pregabalin cohorts with similar demographics, health plan types, geographic regions, comorbid medical conditions, prior health care costs, and prior select medication history (ie, antidepressants, anticonvulsants, opioids, nonsteroidal anti-inflammatory drugs, sleep and antianxiety medications, skeletal muscle relaxants, dopamine agonists, topical agents, and $5-\mathrm{HT}_{3}$ antagonists). A logistic regression predicting the probability of initiating duloxetine versus pregabalin was estimated first. The predicted probability of duloxetine initiation was ranked for all individuals from highest to lowest into 10 strata, so that cross-cohort differences in all intend-to-adjusted variables were not statistically significant at stratum 2 through 9 (based on paired two-tailed $t$-tests for means and proportions). Duloxetine and pregabalin patients in the top or bottom stratum were further excluded because they had the most 
different characteristics. The sample selection flow chart is described in Figure 1. We started with 104,004 duloxetine initiators and 70,137 pregabalin initiators in 2006. The final study sample included 3711 duloxetine patients and 4111 pregabalin patients, respectively.

\section{Common reasons for inpatient and outpatient services}

For both duloxetine and pregabalin patients, Urix's RiskSmart software was used to identify all the medical conditions captured in claims collected over the 12-month post-index period. This RiskSmart software applies a comprehensive disease classification system that automatically organizes comprehensive ICD-9-CM codes (more than 15,000) recorded in administrative claims database into 781 homogeneous clinical categories (DxGroups). ${ }^{36}$ Using the same software, all claims from inpatient admissions, outpatient hospital services, physician office services, and emergency room were processed separately. DxGroups generated from each process were used to identify reasons leading to inpatient admissions, physician office visits, outpatient hospital visits, and emergency room visits, respectively. For all claims collected from physician office visits, primary care (eg, family medicine, internal medicine, pediatrician) versus specialty care (eg, pain medicine and other non-primary care

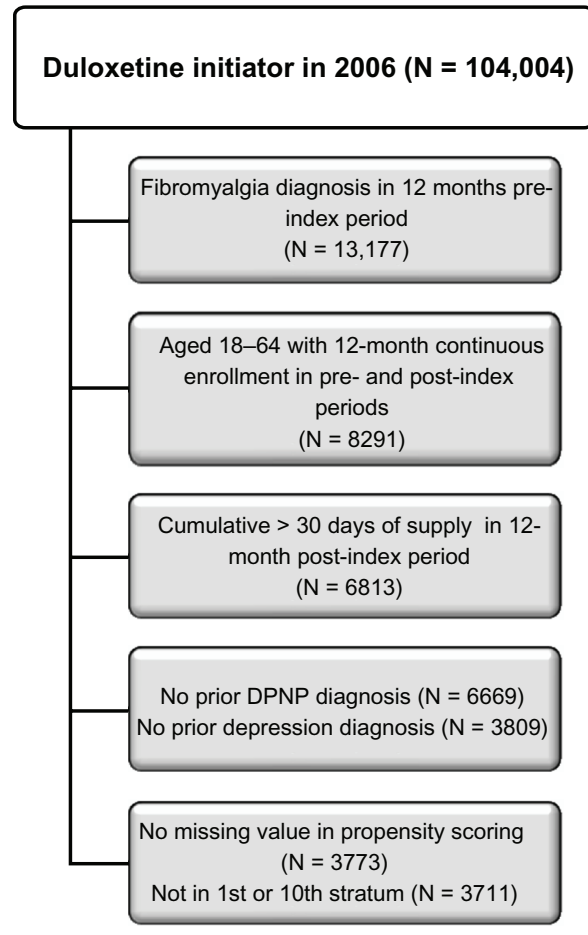

medicine fields) visits were further separated based on physician specialties. Claims from primary versus specialty care visits were examined respectively, and DxGroups were used to identify the reasons leading to each type of visit.

\section{Analysis}

For patients in the duloxetine and pregabalin cohorts, the propensity score-adjusted demographics and health care costs (total, inpatient, outpatient, and pharmacy) over the 12-month pre-index period were examined to show the similarities between groups. ${ }^{35}$ Propensity score-adjusted health care costs over the 12-month post-index period were compared between the duloxetine and pregabalin patients to identify what contributed most to the cross-cohort cost differences. ${ }^{35}$

Mapping the first diagnosis from each inpatient, outpatient hospital, physician office visit, and emergency room claim captured over the 12-month post-index period into a DxGroup category, we examined the most common reasons for inpatient admissions, physician office visits, outpatient hospital visits, and emergency room visits, respectively. Using physician specialty to distinguish further between primary versus specialty care visits for all the claims submitted for physician office visits, the first diagnosis from each claim was mapped into a DxGroup category to analyze the most common reasons

Pregabalin initiators in $2006(\mathrm{~N}=70,137)$

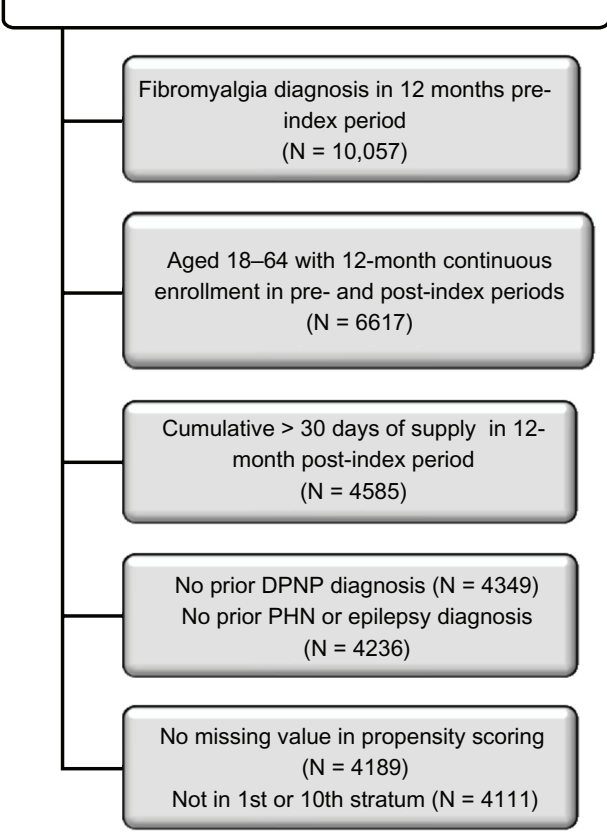

Figure I Sample selection flow chart.

Abbreviations: DPNP, diabetic peripheral neuropathic pain; PHN, post-herpetic neuralgia. 
leading to primary versus specialty care visits. The prevalence per 10,000 persons of inpatient admissions, outpatient hospital visits, physician office visits, emergency room visits, and primary and specialty care visits were compared between the duloxetine and pregabalin cohorts. Logistic regression was used to assess further the incremental contribution of duloxetine versus pregabalin initiation (odds ratio from the logistic regression) to inpatient admissions, outpatient hospital visits, physician office visits, emergency room visits, and primary and specialty care visits, controlling for crosscohort differences. All analyses were performed using SAS version 9.1 (SAS Institute, Cary, NC). $P$ values $<0.05$ were considered to be statistically significant.

\section{Results}

Per study design, both duloxetine and pregabalin patients had similar demographics (mean age 51 years, $83 \%$ females) and health care costs over the 12-month pre-index period (Figure 2). However, duloxetine patients had significantly lower total costs $(\$ 19,378$ versus $\$ 27,045)$ than pregabalin patients during the 12-month post-index period, with most of the cost difference from outpatient services $(\$ 7,552$ versus $\$ 10,643$ ) followed by inpatient services ( $\$ 2351$ versus $\$ 4868$, all $P$ values $<0.05)$.

The most common reasons for inpatient admissions are presented in Table 1 for both the duloxetine and pregabalin patients. Both cohorts shared eight of the 10 most common reasons, and three of the top five reasons were the same, ie, intervertebral disc disorders (herniated, prolapsed, degenerated disc), osteoarthritis of lower leg (knee), and chest pain. Compared with the pregabalin patients, duloxetine patients were less likely to be hospitalized due to an intervertebral disc disorder, major depressive disorder, or spondylosis and allied disorders, eg, osteoarthritis of spine (odds ratios $0.443,0.808$, and 0.355 , respectively), but more likely to be admitted to hospital due to intestinal obstruction (odds ratio 3.229, all $P<0.05$ ).

Table 2 summarizes the leading reasons for physician office visits by patients in both the duloxetine and pregabalin cohorts. All top reasons were shared, with physician office visits due to soft tissue disorders (eg, tendonitis bursitis, muscle tissue disorder) being the most common reason in both cohorts, followed by nonspecific backache/other back/ neck pain (NB/OB/NP) disorders. Controlling for crosscohort differences, duloxetine patients were less likely than pregabalin patients to have physician office visits due to NB/ $\mathrm{OB} / \mathrm{NP}$ or an intervertebral disc disorder (odds ratios 0.689 and 0.622 , respectively, both $P<0.05$ ).

Eight of the 10-11 most common reasons for outpatient hospital visits were shared by both the duloxetine and pregabalin cohorts (Table 3 ). The top three reasons were the same, with other general symptoms being the most common reason followed by soft tissue and NB/OB/NP disorders. Controlling for cross-cohort differences, duloxetine patients were more likely to make an outpatient visit due to other general symptoms (odds ratios 1.428), but less likely to make an outpatient visit due to asthma (except chronic obstructive pulmonary disease) or upper limb neuropathy, eg, carpal tunnel syndrome (odds ratios 0.914 and 0.491 , respectively, all $P<0.05)$.

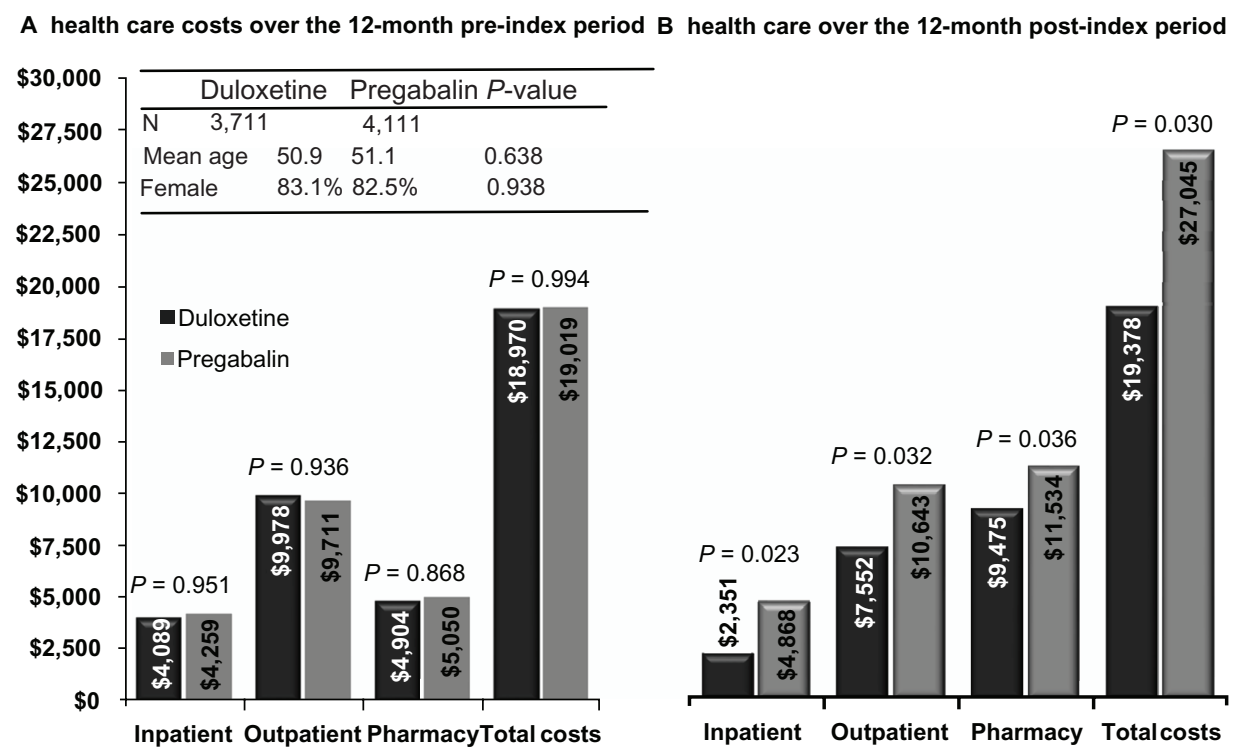

Figure 2 Health care costs over the 12-month pre-index (A) and post-index (B) periods. 
Table I Top reasons for inpatient admissions in the 12-month post-index period

\begin{tabular}{|c|c|c|c|c|c|}
\hline & \multicolumn{2}{|c|}{ Duloxetine } & \multicolumn{2}{|c|}{ Pregabalin } & \multirow{2}{*}{$\begin{array}{l}\text { Odds } \\
\text { ratio }\end{array}$} \\
\hline & Rank & Rates per $10,000^{\wedge}$ & Rank & Rates per $10,000^{\wedge}$ & \\
\hline Intervertebral disc disorders (herniated, prolapsed, degenerated disc) & $\mathbf{I}$ & 598 & $\mathbf{I}$ & 1289 & $0.443 *$ \\
\hline Osteoarthritis of lower leg (knee) & 2 & 578 & 3 & 446 & 1.385 \\
\hline Chest pain & 3 & 498 & 2 & 554 & 0.796 \\
\hline Coronary atherosclerosis and other ischemic heart disease & 4 & 438 & 7 & 313 & $\mathrm{I} .725$ \\
\hline Other and unspecified pneumonia & 5 & 319 & 10 & 253 & 1.274 \\
\hline $\begin{array}{l}\text { Stomach, intestinal disorders, symptoms excluding obstruction, } \\
\text { ulcer, and hemorrhage }\end{array}$ & 6 & 279 & 9 & 301 & 0.825 \\
\hline Spinal stenosis & 7 & 239 & 5 & 361 & 0.742 \\
\hline Major depressive disorders & 8 & 239 & 6 & 361 & $0.808^{*}$ \\
\hline Cellulitis, abscess, other local skin infection & 9 & 239 & 15 & 193 & 1.439 \\
\hline Intestinal obstruction & 10 & 219 & 47 & 84 & $3.229 *$ \\
\hline Spondylosis and allied disorders (osteoarthritis of spine) & 20 & 139 & 4 & 398 & $0.355^{*}$ \\
\hline Poisoning by (unintentional) provider or patient medication error & 30 & 120 & 8 & 313 & 0.469 \\
\hline
\end{tabular}

Notes: ^ 10,000 times the number of inpatient admissions divided by number of individuals in the cohort. Bold text designates reason in the top ten; ${ }^{\circ}$ dds ratio, from the logistic regression predicting any inpatient admission controlling for cross-cohort differences; *statistically significant $P<0.05$.

Table 4 shows the most common reasons for emergency room visits by patients in the duloxetine and pregabalin cohorts. Both cohorts shared all the leading reasons, with the top eight being the same. Chest pain was the leading reason for emergency room visits, with the prevalence rate per 10,000 being 1347 for duloxetine and 1404 for pregabalin. The duloxetine cohort had lower raw emergency room rates than the pregabalin cohort (columns 2 and 4) for all reasons listed except abdominal/pelvic symptoms, contusion/ superficial injury, or migraine headaches. However, none of the predictors of any emergency room visit controlling for cross-cohort differences were statistically significant.

Nine of the 10 most common reasons for primary care visits were the same for both the duloxetine and pregabalin patients, with soft tissue disorders being the leading one (Table 5). The prevalence of primary care visits due to essential hypertension (duloxetine 2375 per 10,000 , third ranking; pregabalin 2366 per 10,000, fourth ranking) or NB/OB/NP (duloxetine 1940 per 10,000, seventh ranking; pregabalin 2570 per 10,000, second ranking) disorders was high. Controlling for cross-cohort differences, duloxetine patients were more likely to make primary care visits due to soft tissue disorders, essential hypertension, other general symptoms, or malaise and fatigue, including chronic fatigue syndrome (odds ratios 1.115, 1.160, 1.142, and 1,227, respectively) than pregabalin patients, but less likely to seek primacy care due to NB/OB/NP or type 2 diabetes without complications (odds ratios 0.836 and 0.833 , respectively, all $P<0.05)$.

Table 6 shows the leading reasons for specialty care visits for patients in both the duloxetine and pregabalin cohorts. Nine of the main reasons for specialty care visits were the same in both cohorts, and soft tissue disorders were the most common reason leading to a specialty care visit.

Table 2 Top reasons for physician office visits in the 12-month post-index period

\begin{tabular}{|c|c|c|c|c|c|}
\hline & \multicolumn{2}{|c|}{ Duloxetine } & \multicolumn{2}{|c|}{ Pregabalin } & \multirow{2}{*}{$\begin{array}{l}\text { Odds } \\
\text { ratio }\end{array}$} \\
\hline & Rank & Rates per $10,000^{\wedge}$ & Rank & Rates per $10,000^{\wedge}$ & \\
\hline Disorders of soft tissue (eg, tendonitis, bursitis, muscle disorders) & $\mathbf{I}$ & 5922 & $\mathbf{I}$ & 6123 & 0.911 \\
\hline Nonspecific backache/other back/neck pain/disorders & 2 & 3983 & 2 & 5498 & $0.689 *$ \\
\hline Screening/observation/special examinations & 3 & 3396 & 5 & 3101 & 0.987 \\
\hline Other general symptoms & 4 & 3366 & 3 & 3485 & 1.031 \\
\hline Arthropathy/joint disorders, derangements, joint pain/stiffness, excluding gout & 5 & 3034 & 4 & 3348 & 0.962 \\
\hline Acute nose/throat infection (eg, common cold) & 6 & 2830 & 7 & 2714 & 1.037 \\
\hline Vaccination/medical examination, other preventive & 7 & 2504 & 9 & 2469 & 1.065 \\
\hline Essential hypertension & 8 & 2463 & 8 & 2626 & 1.052 \\
\hline Disorders of lipoid metabolism (high cholesterol), except lipidoses & 9 & 2202 & 10 & 2197 & 1.075 \\
\hline Screening for malignant neoplasm & 10 & 2156 & 11 & 1905 & 1.092 \\
\hline Intervertebral disc disorders (herniated, prolapsed, degenerated disc) & 11 & 1724 & 6 & 3052 & $0.622^{*}$ \\
\hline
\end{tabular}

Notes: ${ }^{\wedge} 10,000$ times the number of physician office visits divided by number of individuals in the cohort. Bold text designates reason in the top ten; ${ }^{\circ}$ odds ratio, from the logistic regression predicting any physician office visit controlling for cross-cohort differences; *statistically significant $P<0.05$. 
Table 3 Top reasons for outpatient hospital visits in the 12-month post-index period

\begin{tabular}{|c|c|c|c|c|c|}
\hline & \multicolumn{2}{|c|}{ Duloxetine } & \multicolumn{2}{|c|}{ Pregabalin } & \multirow{2}{*}{$\begin{array}{l}\text { Odds } \\
\text { ratio }\end{array}$} \\
\hline & Rank & Rates per $10,000^{\wedge}$ & Rank & Rates per $10,000^{\wedge}$ & \\
\hline Other general symptoms & I & 2954 & I & 2220 & $1.428 *$ \\
\hline Disorders of soft tissue (eg, tendonitis, bursitis, muscle disorders) & 2 & 954 & 3 & 1001 & 0.946 \\
\hline Nonspecific backache/other back/neck pain/disorders & 3 & 940 & 2 & 1383 & 0.737 \\
\hline Type 2 diabetes without complications & 4 & 662 & 5 & 737 & 0.884 \\
\hline Arthropathy/joint disorders, derangements, joint pain/stiffness, excluding gout & 5 & 570 & 6 & 646 & 0.903 \\
\hline Intervertebral disc disorders (herniated, prolapsed, degenerated disc) & 6 & 464 & 4 & 764 & 0.659 \\
\hline Emphysema/chronic bronchitis & 7 & 437 & 7 & 428 & 1.067 \\
\hline Osteoarthritis, not specified to be spine, hip, or knee & 8 & 397 & 10 & 264 & 1.722 \\
\hline Sprains & 9 & 358 & 11 & 264 & 1.334 \\
\hline Asthma, except chronic obstructive & 10 & 225 & 12 & 227 & $0.914^{*}$ \\
\hline Neuropathy of upper limb (eg, carpal tunnel syndrome) & 12 & 212 & 8 & 346 & $0.49 I^{*}$ \\
\hline Spinal stenosis & 17 & 159 & 9 & 291 & 0.644 \\
\hline
\end{tabular}

Notes: ${ }^{\wedge} 10,000$ times the number of outpatient hospital visits divided by number of individuals in the cohort. Bold text designates reason in the top ten; ${ }^{\circ}$ odds ratio, from the logistic regression predicting any outpatient hospital visit controlling for cross-cohort differences; *statistically significant $P<0.05$.

The duloxetine cohort had lower raw specialty care rates than the pregabalin cohort for all reasons listed, except screening for a malignant neoplasm or screening, observation, and special examinations. Controlling for cross-cohort differences, duloxetine patients were more likely to make a specialty care visit due to screening for a malignant neoplasm (odds ratio 1.132), but were less likely to attend to specialty care due to a soft tissue, $\mathrm{NB} / \mathrm{OB} / \mathrm{NP}$, or intervertebral disc disorder, or for spondylosis or an allied disorder (odds ratios 0.835 , $0.693,0.629$, and 0.719 , respectively, all $P<0.05$ ).

\section{Discussion}

Using a large US administrative claims database on similar commercially insured patients with fibromyalgia who initiated duloxetine or pregabalin in 2006, this study was the first to use a comprehensive disease classification to examine the most common reasons leading to inpatient admissions, physician office visits, outpatient hospital visits, emergency room visits, and primary care and specialty care visits. Although duloxetine patients had significantly lower total health care costs than pregabalin patients over the 12-month post-index periods, with most of the cost difference from outpatient services followed by inpatient services (for a detailed discussion, please see our previous publication), ${ }^{35}$ patients in both cohorts shared eight or nine of the top 10 most common reasons for inpatient admissions and outpatient visits. The top three leading reasons for inpatient admissions and outpatient hospital visits, top five reasons for physician office visits, and top eight reasons for emergency room visits were the same for both duloxetine and pregabalin patients.

This study had several interesting findings. First, soft tissue disorders were the leading reason for physician office visits, including both primary and specialty care visits; it was also one of the most common reasons for outpatient

Table 4 Top reasons for emergency room visits in the 12-month post-index period

\begin{tabular}{|c|c|c|c|c|c|}
\hline & \multicolumn{2}{|c|}{ Duloxetine } & \multicolumn{2}{|c|}{ Pregabalin } & \multirow{2}{*}{$\begin{array}{l}\text { Odds } \\
\text { ratio }\end{array}$} \\
\hline & Rank & Rates per $10,000^{\wedge}$ & Rank & Rates per $10,000^{\wedge}$ & \\
\hline Chest pain & I & 1347 & I & 1404 & 0.958 \\
\hline Abdominal/pelvis symptoms & 2 & 1313 & 3 & 1240 & 1.006 \\
\hline Contusion/superficial injury & 3 & 1153 & 4 & 985 & 1.183 \\
\hline Nonspecific backache/other back/neck pain/disorders & 4 & 925 & 2 & 1276 & 0.83 \\
\hline Sprains & 5 & 925 & 5 & 930 & 1.077 \\
\hline Headache excluding migraine & 6 & 753 & 6 & 866 & 0.949 \\
\hline Disorders of soft tissue (eg, tendonitis, bursitis, muscle disorders) & 7 & 719 & 7 & 802 & 0.88 \\
\hline $\begin{array}{l}\text { Stomach/intestinal disorders/symptoms, except obstruction, ulcer, } \\
\text { and hemorrhage }\end{array}$ & 8 & 605 & 8 & 766 & 0.795 \\
\hline Migraine headaches & 9 & 594 & 11 & 520 & 1.133 \\
\hline Other general symptoms & 10 & 571 & 9 & 647 & 1.109 \\
\hline Arthropathy/joint disorders, derangements, joint pain/stiffness, excluding gout & 11 & 525 & 10 & 574 & 0.861 \\
\hline
\end{tabular}

Notes: ${ }^{\wedge} 10,000$ times the number of emergency room visits divided by number of individuals in the cohort. Bold text designates reason in the top ten; ${ }^{\dagger}$ odds ratio, from the logistic regression predicting any emergency room visits controlling for cross-cohort differences. 
Table 5 Top reasons for primary care visits in 12-month post-index period

\begin{tabular}{|c|c|c|c|c|c|}
\hline & \multicolumn{2}{|c|}{ Duloxetine } & \multicolumn{2}{|c|}{ Pregabalin } & \multirow{2}{*}{$\begin{array}{l}\text { Odds } \\
\text { ratio }^{\dagger}\end{array}$} \\
\hline & Rank & Rates per $10,000^{\wedge}$ & Rank & Rates per $10,000^{\wedge}$ & \\
\hline Disorders of soft tissue (eg, tendonitis, bursitis, muscle disorders) & $\mathbf{I}$ & 3667 & $\mathbf{I}$ & 3296 & $1.115^{*}$ \\
\hline Acute nose/throat infection (eg, common cold) & 2 & 2592 & 3 & 2494 & 1.043 \\
\hline Essential hypertension & 3 & 2375 & 4 & 2366 & $1.160 *$ \\
\hline Vaccination/medical examination, other preventive & 4 & 2273 & 5 & 2261 & 1.054 \\
\hline Other general symptoms & 5 & 2248 & 6 & 2155 & $1.142 *$ \\
\hline Disorders of lipoid metabolism (high cholesterol), except lipidoses & 6 & 1965 & 7 & 1999 & 1.029 \\
\hline Nonspecific backache/other back/neck pain/disorders & 7 & 1940 & 2 & 2570 & $0.836 *$ \\
\hline Arthropathy/joint disorders, derangements, joint pain/stiffness, excluding gout & 8 & 1534 & 8 & 1509 & 1.105 \\
\hline Malaise and fatigue, including chronic fatigue syndrome & 9 & $|34|$ & 13 & 1097 & $1.227^{*}$ \\
\hline Acute or unspecific bronchitis bronchiolitis & 10 & 1170 & 9 & 1256 & 1.011 \\
\hline Type 2 diabetes without complications & 14 & 931 & 10 & 1166 & $0.833^{*}$ \\
\hline
\end{tabular}

Notes: ${ }^{\wedge} 10,000$ times the number of primary care visits divided by number of individuals in the cohort. Bold text designates reason in the top ten; ${ }^{\circ}$ odds ratio, from the logistic regression predicting any primary care visit controlling for cross-cohort differences; *statistically significant $P<0.05$.

hospital visits (ranked second for duloxetine, and third for pregabalin) and emergency room visits (seventh ranking for both duloxetine and pregabalin). Controlling for cross-cohort differences, duloxetine patients were more likely to have a primary care visit due to soft tissue disorders than pregabalin patients. Given its high prevalence in various health care encounters and different use of primary care versus specialty care setting, future research may need to explore further how soft tissue disorders are treated in real-world practice when managing fibromyalgia.

Second, the prevalence rate for NB/OB/NP was very high across the care settings, ie, the second most common reason for physician office visits, the third (duloxetine) and second (pregabalin) leading reason for outpatient hospital visits, the seventh (duloxetine) and second (pregabalin) most common reason for primary care visits, and the fourth (duloxetine) and second (pregabalin) leading reason for specialty care visits. Controlling for cross-cohort differences, duloxetine patients were less likely to go to the physician's office in either the primary or specialty care setting due to $\mathrm{NB} / \mathrm{OB} / \mathrm{NP}$ than were pregabalin patients. The higher physician office use of $\mathrm{NB} /$ $\mathrm{OB} / \mathrm{NP}$ among pregabalin patients may impact health care costs, and further research might be warranted.

Third, intervertebral disc disorder was the leading cause of inpatient admissions for both duloxetine and pregabalin patients, and its prevalence was also high for outpatient visits (duloxetine sixth, pregabalin fourth), specialty care (duloxetine seventh, pregabalin fourth), and physician office visits (duloxetine eleventh, pregabalin sixth). Controlling for cross-cohort differences, duloxetine patients were less likely than pregabalin patients to go to each of the care settings mentioned above, except for outpatient hospital visits. Why intervertebral disc disorder is managed differently between duloxetine and pregabalin patients and how the different use of health care systems may impact health care costs needs to be examined in future studies.

Table 6 Top reasons for specialty care visits in the 12-month post-index period

\begin{tabular}{|c|c|c|c|c|c|}
\hline & \multicolumn{2}{|c|}{ Duloxetine } & \multicolumn{2}{|c|}{ Pregabalin } & \multirow{2}{*}{$\begin{array}{l}\text { Odds } \\
\text { ratio }^{\dagger}\end{array}$} \\
\hline & Rank & Rates per $10,000^{\wedge}$ & Rank & Rates per $10,000^{\wedge}$ & \\
\hline Disorders of soft tissue (eg, tendonitis, bursitis, muscle disorders) & I & 3895 & I & 4449 & $0.835 *$ \\
\hline Screening for malignant neoplasm & 2 & 3367 & 5 & 2825 & $1.132 *$ \\
\hline Screening/observation/special exams & 3 & 3049 & 3 & 3031 & 0.904 \\
\hline Nonspecific backache/other back/neck pain/disorders & 4 & 3046 & 2 & 4402 & $0.693^{*}$ \\
\hline Arthropathy/joint disorders, derangements, joint pain/stiffness, excluding gout & 5 & 2456 & 6 & 2786 & 0.939 \\
\hline Other general symptoms & 6 & 2415 & 7 & 2693 & 0.935 \\
\hline Intervertebral disc disorders (herniated, prolapsed, degenerated disc) & 7 & 1742 & 4 & 3031 & $0.629 *$ \\
\hline Abdominal/pelvis symptoms & 8 & 1672 & 8 & 1761 & 1.024 \\
\hline Chest pain & 9 & 1395 & 9 & 1658 & 0.928 \\
\hline $\begin{array}{l}\text { Stomach/intestinal disorders/symptoms, except obstruction, ulcer, } \\
\text { and hemorrhage }\end{array}$ & 10 & 1202 & II & 1306 & 0.959 \\
\hline Spondylosis and allied disorders (osteoarthritis of spine) & 14 & 843 & 10 & 1436 & $0.719 *$ \\
\hline
\end{tabular}

Notes: ${ }^{\wedge} 10,000$ times the number of specialty care visits divided by number of individuals in the cohort. Bold text designates reason in the top ten; ${ }^{\circ}$ odds ratio, from the logistic regression predicting any specialty care visit controlling for cross-cohort differences; *statistically significant $P<0.05$. 
Lastly, chest pain was the most common reason for emergency room visits by patients in both cohorts, and it was also the main reason for inpatient admissions (third and second for duloxetine and pregabalin, respectively), and specialty care visits (ninth for both duloxetine and pregabalin). The prevalence was similar between the cohorts, and no statistically significant result was found controlling for cross-cohort differences. Because inpatient admissions and emergency room visits are costly, managing the top reasons leading to emergency room visits as well as hospitalization effectively may potentially reduce overall health care costs.

This study has several limitations. First, because of its retrospective design, this analysis can only describe the different reasons leading to inpatient and outpatient care. What caused the different use in the different care settings could be not identified. Second, ICD-9-CM diagnosis codes were used to identify all medical conditions captured in the administrative claims database. Therefore, medical conditions not recorded anywhere in the database analyzed here were not recognized. Third, all patients included were from a large, geographically diverse commercial population covered by large employer-sponsored private health insurance, so findings from this study may not be generalizable to other populations with different characteristics. Fourth, non-pharmacological management for fibromyalgia was not addressed in this study, so its impact on inpatient and outpatient care is unknown. Finally, all patients were required to have continuous enrollment during the 12-month pre-index and post-index periods. Any patients who dropped out of the health plan anytime before or after the index date were not included.

\section{Conclusion}

Among similar commercially insured patients with fibromyalgia, those initiated on duloxetine had significantly lower health care costs over the 12-month post-index period than those who initiated pregabalin. The leading reasons for inpatient or outpatient visits were also somewhat different.

\section{Disclosure}

Data from this study were presented in poster form at the European International Society for Pharmacoeconomics and Outcomes Research 2011 meeting held in Madrid, Spain.

\section{References}

1. National Institute of Arthritis and Musculoskeletal and Skin Diseases. Fibromyalgia, 1999. Available from: http://www.niams.nih.gov/ Health_Info/Fibromyalgia/default.asp. Accessed May 5, 2009.
2. Topbas M, Cakirbay H, Gulec H, Akgol E, Ak I, Can G. The prevalence of fibromyalgia in women aged 20-64 in Turkey. Scand J Rheumatol. 2005;34(2):140-144.

3. Weir PT, Harlan GA, Nkoy FL, et al. The incidence of fibromyalgia and its associated comorbidities: a population-based retrospective cohort study based on International Classification of Diseases, 9th Revision codes. J Clin Rheumatol. 2006;12(3):124-128.

4. Toda K. The prevalence of fibromyalgia in Japanese workers. Scand J Rheumatol. 2007;36(2):140-144.

5. Mas AJ, Carmona L, Valverde M, Ribas B. Prevalence and impact of fibromyalgia on function and quality of life in individuals from the general population: results from a nationwide study in Spain. Clin Exp Rheumatol. 2008;26(4):519-526.

6. National Fibromyalgia Association. Prevalence of fibromyalgia, 2009. Available from: http://www.fmaware.org/site/PageServer?pagename= fibromyalgia_affected. Accessed May 5, 2009.

7. Wrong Diagnosis. Prevalence and incidence of fibromyalgia, 2009. Available from: http://www.wrongdiagnosis.com/f/fibromyalgia/stats. htm. Accessed May 5, 2009.

8. Wolfe F, Petri M, Alarcon GS, et al. Fibromyalgia, systemic lupus erythematosus (SLE), and evaluation of SLE activity. J Rheumatol. 2009;36(1):82-88.

9. Wolfe F, Hawley DJ, Goldenberg DL, Russell IJ, Buskila D, Neumann L. The assessment of functional impairment in fibromyalgia (FM): Rasch analyses of 5 functional scales and the development of the FM Health Assessment Questionnaire. J Rheumatol. 2000;27(8):1989-1999.

10. Wolfe F, Smythe HA, Yunus MB, et al. The American College of Rheumatology 1990 Criteria for the Classification of Fibromyalgia. Report of the Multicenter Criteria Committee. Arthritis Rheum. 1990;33(2):160-172.

11. Branco JC, Bannwarth B, Failde I, et al. Prevalence of fibromyalgia: a survey in five European countries. Semin Arthritis Rheum. 2010;39(6): 448-453.

12. Bannwarth B, Blotman F, Roue-Le Lay K, Caubere JP, Andre E, Taieb C. Fibromyalgia syndrome in the general population of France: a prevalence study. Joint Bone Spine. 2009;76(2):184-187.

13. Schochat $\mathrm{T}$, Raspe H. Elements of fibromyalgia in an open population. Rheumatology (Oxford). 2003;42(7):829-835.

14. Bazelmans E, Vercoulen JH, Galama JM, van Weel C, van der Meer JW, Bleijenberg G. Prevalence of chronic fatigue syndrome and primary fibromyalgia syndrome in The Netherlands. Ned Tijdschr Geneeskd. 1997;141(31):1520-1523. Dutch.

15. Wolfe F, Hawley DJ, Wilson K. The prevalence and meaning of fatigue in rheumatic disease. J Rheumatol. 1996;23(8):1407-1417.

16. Sardini S, Ghirardini M, Betelemme L, Arpino C, Fatti F, Zanini F. Epidemiological study of a primary fibromyalgia in pediatric age. Minerva Pediatr. 1996;48(12):543-550. Italian.

17. Wolfe F, Ross K, Anderson J, Russell IJ, Hebert L. The prevalence and characteristics of fibromyalgia in the general population. Arthritis Rheum. 1995;38(1):19-28.

18. Buskila D, Neumann L, Hershman E, Gedalia A, Press J, Sukenik S. Fibromyalgia syndrome in children - an outcome study. J Rheumatol. 1995;22(3):525-528.

19. Pagano T, Matsutani LA, Ferreira EA, Marques AP, Pereira CA. Assessment of anxiety and quality of life in fibromyalgia patients. Sao Paulo Med J. 2004;122(6):252-258.

20. Ozcetin A, Ataoglu S, Kocer E, et al. Effects of depression and anxiety on quality of life of patients with rheumatoid arthritis, knee osteoarthritis and fibromyalgia syndrome. West Indian Med J. 2007;56(2): 122-129.

21. Theadom A, Cropley M, Humphrey KL. Exploring the role of sleep and coping in quality of life in fibromyalgia. J Psychosom Res. 2007;62(2): 145-151.

22. Schoofs N, Bambini D, Ronning P, Bielak E, Woehl J. Death of a lifestyle: the effects of social support and healthcare support on the quality of life of persons with fibromyalgia and/or chronic fatigue syndrome. Orthop Nurs. 2004;23(6):364-374. 
23. Verbunt JA, Pernot DH, Smeets RJ. Disability and quality of life in patients with fibromyalgia. Health Qual Life Outcomes. 2008;6:8.

24. Tander B, Cengiz K, Alayli G, Ilhanli I, Canbaz S, Canturk F. A comparative evaluation of health related quality of life and depression in patients with fibromyalgia syndrome and rheumatoid arthritis. Rheumatol Int. 2008;28(9):859-865.

25. Salaffi F, Sarzi-Puttini P, Girolimetti R, Atzeni F, Gasparini S, Grassi W. Health-related quality of life in fibromyalgia patients: a comparison with rheumatoid arthritis patients and the general population using the SF-36 health survey. Clin Exp Rheumatol. 2009;27(5 Suppl 56):S67-S74.

26. Carville SF, Arendt-Nielsen S, Bliddal H, et al. EULAR evidence-based recommendations for the management of fibromyalgia syndrome. Ann Rheum Dis. 2008;67(4):536-541.

27. Guymer EK, Littlejohn GO. Fibromyalgia. Diagnosis and management. Australas Chiropr Osteopathy. 2002;10(2):81-84.

28. Sumpton JE, Moulin DE. Fibromyalgia: presentation and management with a focus on pharmacological treatment. Pain Res Manag. 2008; 13(6):477-483.

29. Buckhardt CS, Goldenberg D, Crofford L, et al. Guideline for the Management of Fibromyalgia Syndrome Pain in Adults and Children. APS Clinical Practice Guideline Series No 4. Glenview, IL: American Pain Society; 2005.
30. Hauser W, Thieme K, Turk DC. Guidelines on the management of fibromyalgia syndrome - a systematic review. Eur J Pain. 2010;14(1): $5-10$.

31. Forseth KK, Gran JT. Management of fibromyalgia: what are the best treatment choices? Drugs. 2002;62(4):577-592.

32. Brosseau L, Wells GA, Tugwell P, et al. Ottawa Panel evidence-based clinical practice guidelines for aerobic fitness exercises in the management of fibromyalgia: part 1. Phys Ther. 2008;88(7):857-871.

33. Brosseau L, Wells GA, Tugwell P, et al. Ottawa Panel evidence-based clinical practice guidelines for strengthening exercises in the management of fibromyalgia: part 2. Phys Ther. 2008;88(7):873-886.

34. Crofford LJ. Pain management in fibromyalgia. Curr Opin Rheumatol. 2008;20(3):246-250.

35. Zhao Y, Sun P, Watson P, Mitchell B, Swindle R. Comparison of medication adherence and healthcare costs between duloxetine and pregabalin initiators among patients with fibromyalgia. Pain Pract. 2010;11(3):204-216.

36. Zhao Y, Ash AS, Ellis RP, Slaughter JP. Disease burden profiles: an emerging tool for managing managed care. Health Care Manag Sci. 2002;5(3):211-219.
Journal of Pain Research

\section{Publish your work in this journal}

The Journal of Pain Research is an international, peer-reviewed, open access, online journal that welcomes laboratory and clinical findings in the fields of pain research and the prevention and management of pain. Original research, reviews, symposium reports, hypothesis formation and commentaries are all considered for publication.

\section{Dovepress}

The manuscript management system is completely online and includes a very quick and fair peer-review system, which is all easy to use. Visit http://www.dovepress.com/testimonials.php to read real quotes from published authors. 